\title{
SEVERITY OF CHRONIC ASTHMA IN CHILDREN 2 TO 12 YEARS, PRESENTING TO A TERTIARY CARE HOSPITAL.
}

1. MBBS, FCPS Registrar Pediatrics Liaquat National Hospital Karachi. 2. MBBS, FCPS

Assistant Professor Pediatrics LUMHS, Jamshoro.

3. MBBS

House Officer JPMC, Karachi.

4. Student Physiotherapy DUMHS Karachi.

Correspondence Address: Dr. Muhammad Nadeem Chohan House \# A-251 Phase-1 Sindh University,

Housing Employee Cooperative Society Jamshoro, Sindh.

nadeem.chohan@lumhs.edu.pk

Article received on:

$19 / 12 / 2017$

Accepted for publication: $18 / 04 / 2019$

\begin{abstract}
Muhmmad Athar Ahmed', Muhammad Nadeem Chohan², Nehan Adil Khan ${ }^{3}$, Tarim Nayab4
\end{abstract}
\begin{abstract}
Objectives: To determine the frequency of severity of Chronic asthma (never taken controller therapy) in children 2 to 12 years, presenting to Pediatric Out Door Department. Liaquat National Hospital Karachi. Study Design: Descriptive Cross-Sectional Study. Setting: Department of Pediatrics Medicine, Liaquat National Hospital Karachi. Period: From June 2016 to December 2016. Material \& Methods: A total of 106 children with symptoms of airflow obstruction characterized by recurrent cough, difficulty in breathing and wheeze were included in this study. All the study subjects were asked about clinical symptoms and on the basis of that severity of asthma were classified as mild, moderate or severe asthma. Results: The average age of the children was $6.38 \pm 6.0$ years. In this study, intermittent asthma was observed in $24(22.64 \%)$ cases. There were 30(28.6\%) children with mild persistant asthma, 40(37.74\%) children with moderate persistant asthma and severe persistant asthma was found in 12(11.32\%) children. Conclusion: We found moderate persistent asthma, as the most frequent category, while severe persistent asthma was the least frequent category. Age had the significant effect on the asthma frequency; it was most common in less than 10 years old children. Duration of asthma and gender had no effect on asthma severity, while weight and height had a significant effect on asthma severity.
\end{abstract}

Key words: Asthma, Bronchoconstriction.

Article Citation: Ahmed MA, Chohan MN, Khan NA, Nayab T. Severity of chronic asthma in children 2 to 12 years, presenting to a Tertiary Care Hospital. Professional Med J 2020; 27 (3):667-672. DOI: 10.29309/TPMJ/2020.27.3.4596

\section{INTRODUCTION}

In developing countries, asthma is probably the most common chronic respiratory illness after tuberculosis. ${ }^{1}$ It is both underdiagnosed and undertreated. ${ }^{2}$ Asthma is a chronic inflammatory obstructive lung disease having reversible hyper responsiveness of air ways. ${ }^{3}$ Asthma affects 300 million people worldwide, and its prevalence and severity are increasing in many developing countries. ${ }^{4,5}$ its prevalence in children is estimated to be around $10 \%{ }^{6}$

Asthma is a well recognized health problem in Pakistan. Exact Prevalence of childhood asthma in Pakistan is not known, due to a lack of epidemiological studies. Study done in Karachi (2012- 2013) showed the overall prevalence of asthma among children was $10.2 \%{ }^{7}$

Delay in recognizing the severity of asthma and prompt alterations in therapeutic regimen increases the morbidity and mortality. ${ }^{8}$ Chronic asthma in patients of 2-18 years of age is treated on the basis of its severity. Intermittent asthma is managed with only short-acting beta 2 agonist, Persistent mild asthma is treated with a short acting beta 2 agonist and low dose inhaled corticosteroids, persistent moderate asthma is treated with medium dose inhaled corticosteroids with long acting beta 2 agonist and persistent severe asthma is treated with high dose inhaled corticosteroid. ${ }^{9}$

Our hypothesis is that chronic asthma is under treated in our country. Categorization between intermittent and persistent asthma is not made by primary physicians, that why controller drugs are not prescribed. These factors can lead to severe acute asthma and status asthma (a life threatening condition).

The aim of our study is that by knowing the 
frequency of chronic asthma severity in children not taking controller drugs, we can council primary physicians and parents to use controller drugs to decrease the morbidity and mortality by this preventable condition.

\section{OBJECTIVES}

To determine the frequency of severity of Chronic asthma (never taken controller therapy) in children 2 to 12 years, presenting to Pediatric Out Door Department. Liaquat National Hospital Karachi.

\section{METHODOLOGY}

This Cross sectional study was done at Out Patient Department of Pediatric Medicine, Liaquat National Hospital Karachi from June 2016 to December 2016. Total 106 study subjects were included in the study with Non probability consecutive sampling technique. WHO software for sample size determination was used considering $P=13.33 \%{ }^{2}, d=6.5 \%$, with 95\% confidence level. Inclusion Criteria were age between 2 to 12 years of either Sex with symptoms of airflow obstruction characterized by recurrent cough, difficulty in breathing and wheeze. Children having Known or suspected immunodeficiency, Known case of congenital heart disease, Neurologically impaired children (as they are at risk for recurrent aspiration), Lung diseases like Tuberculosis, bronchiectasis, cystic adenomatoid malformation of lung and Known case of cystic fibrosis were excluded from study. Children who were taking controller medicines or if they visited the Emergency department, or hospitalized due to asthma in previous 1 month, were also excluded from the study.

Children fulfilling the inclusion criteria were included in the study after taking informed consent from the parents/care takers. Patients' demographics, detailed clinical history and physical examinations were done by the principal investigator. All the study subjects were asked about clinical symptoms and on the basis of their responses, severity of asthma (as per operation definition) was classified as mild persistent, moderate persistent or severe persistent asthma. All data about patients' demographics, history, physical examination, severity of asthma was recorded by principal investigator on a predesigned Performa. Data was analyzed in SPSS version 22. Mean \pm SD was calculated for quantitative variables i.e. Age, weight, height, and disease duration. For qualitative variables (gender and severity of asthma) frequency and percentage were calculated. Stratification was done for gender, age, weight, height and duration of asthma to see the effect of these on severity of asthma, chi square test and one way ANOVA were applied respectively, at $95 \% \mathrm{Cl}$ and $\mathrm{p}$ value $\leq 0.05$ was considered as significant.

\section{Operational Definitions}

\section{Asthma}

Presence of any two or more of the following symptoms of airflow obstruction more than 4 times in the previous year characterized by: cough, shortness of breath/fast breathing or presence of wheeze

\section{Severe Persistent Asthma}

Patient with continuous day time symptoms (as stated above) and frequent night symptoms ( $>3$ times per week). ${ }^{10}$

\section{Moderate Persistent Asthma}

Patient with daily day time symptoms and night symptoms $>1$ per week.

\section{Mild Persistent Asthma}

Patient with day time symptoms $>2$ times per week and night symptoms $>2$ times per month.

\section{Intermittent Asthma}

Patient with day time symptoms $\leq 2$ times per week and night time symptoms $<2$ times per month.

\section{Controller Medicines}

Inhaled Steroids, Long acting Beta agonist, Leukotriene Inhibiters.

\section{RESULTS}

A total of 106 children with symptoms of airflow obstruction characterized by recurrent cough, difficulty in breathing and wheeze were included in this study. Most of the children were below 10 
years of age as presented in Table-l. The average age of the children was $6.38 \pm 6.0$ years similarly average weight, height and duration of asthma is also presented in Table-II. Out of 106 patients, $59.43 \%$ were male and $40.57 \%$ were female (Table-I).

In this study, intermittent asthma was observed in $24(22.64 \%)$ cases. There were $30(28.6 \%)$ children with mild persistent asthma, 40(37.74\%) children with moderate persistent asthma and
12(11.32\%) children with severe persistent asthma, as presented in Figure-1. Frequency of severity of asthma was significant among different age groups as shown in Table-III while it was insignificant between male and female (TableIV). Severity of asthma was also associated with weight and height as presented in Table-V and VI respectively. It was also observed that severity of asthma was not significantly associated with duration of asthma (Table-VII).

\begin{tabular}{|l|c|}
\hline \multicolumn{1}{|c|}{ Age } & Number (Percentage) \\
\hline 2-5 Years & $47(44.34 \%)$ \\
\hline $6-10$ Years & $44(41.51 \%)$ \\
\hline$>10$ Years & $15(14.15 \%)$ \\
\hline Gender & $63(59.43 \%)$ \\
\hline Male & $43(40.57 \%)$ \\
\hline Female & \\
\hline
\end{tabular}

Table-I. Age and gender distribution of the patients $n=106$

\begin{tabular}{|c|c|c|c|c|c|}
\hline & & Age (Years) & Weight (kg) & $\begin{array}{l}\text { Height } \\
\text { (cm) }\end{array}$ & $\begin{array}{c}\text { Duration of Asthma } \\
\text { (Months) }\end{array}$ \\
\hline \multicolumn{2}{|l|}{ Mean } & 6.38 & 18.35 & 115.81 & 23.76 \\
\hline \multirow{2}{*}{$\begin{array}{l}95 \% \text { Confidence Interval } \\
\text { for Mean }\end{array}$} & Lower Bound & 5.78 & 16.90 & 112.28 & 21.60 \\
\hline & Upper Bound & 6.97 & 19.79 & 119.34 & 25.93 \\
\hline Interquartile Range & & 5.6 & 12 & 30 & 22 \\
\hline
\end{tabular}

Table-II. Descriptive statistics of demographic characteristics and duration of asthma of the patients

\begin{tabular}{|c|c|c|c|}
\hline \multirow[b]{2}{*}{ Severity } & \multicolumn{3}{|c|}{ Age Groups (Years) } \\
\hline & $\begin{array}{l}2 \text { to } 5 \text { Years } \\
n=47\end{array}$ & $\begin{array}{l}6 \text { to } 10 \text { Years } \\
n=44\end{array}$ & $\begin{array}{l}>10 \text { Years } \\
n=15\end{array}$ \\
\hline Mild & $22(46.8 \%)$ & $7(15.9 \%)$ & $1(6.7 \%)$ \\
\hline Moderate & $11(23.4 \%)$ & $22(50 \%)$ & $7(46.7 \%)$ \\
\hline \multicolumn{4}{|c|}{$\begin{array}{l}\text { Table-III. Frequency of severity of asthma in children with respect to age groups } n=106 \\
\text { Chi-Square }=38.87 p=0.0005\end{array}$} \\
\hline
\end{tabular}

\begin{tabular}{|c|c|c|}
\hline Severity & Male & Female \\
\hline Intermittent & $13(20.6 \%)$ & $11(25.6 \%)$ \\
\hline Mild & 18(28.6\%) & $12(27.9 \%)$ \\
\hline Moderate & $26(41.3 \%)$ & $14(32.6 \%)$ \\
\hline Severe & $6(9.5 \%)$ & $6(14 \%)$ \\
\hline
\end{tabular}




\begin{tabular}{|c|c|c|}
\hline Severity & Weight $\leq 16 \mathrm{~kg}$ & Weight $>16 \mathrm{~kg}$ \\
\hline Intermittent & 14(26.4\%) & $10(18.9 \%)$ \\
\hline Mild & $21(39.6 \%)$ & $9(17 \%)$ \\
\hline Severe & $3(5.7 \%)$ & $9(17 \%)$ \\
\hline
\end{tabular}

\begin{tabular}{|c|c|c|}
\hline Severity & Height $\leq 116 \mathrm{~cm}$ & Height $>116 \mathrm{~cm}$ \\
\hline Intermittent & $13(25 \%)$ & $11(20.4 \%)$ \\
\hline Mild & $24(46.2 \%)$ & $6(11.1 \%)$ \\
\hline Severe & $3(5.8 \%)$ & $9(16.7 \%)$ \\
\hline
\end{tabular}

\begin{tabular}{|l|c|c|}
\hline \multicolumn{1}{|c|}{ Severity of Asthma } & \multicolumn{2}{c|}{ Duration of Asthma } \\
\hline Intermittent & $\mathbf{5 2 4}$ Months & $\mathbf{2 4}$ Months \\
\hline Mild & $\mathbf{8}(16.3 \%)$ & $16(28.1 \%)$ \\
\hline Moderate & $16(32.7 \%)$ & $21(36.8 \%)$ \\
\hline Severe & $19(38.8 \%)$ & $6(10.5 \%)$ \\
\hline \multicolumn{2}{|c|}{ Table-VII. Frequency of severity of asthma in children with respect to duration of asthma $\mathbf{n = 1 0 6}$} \\
\end{tabular}

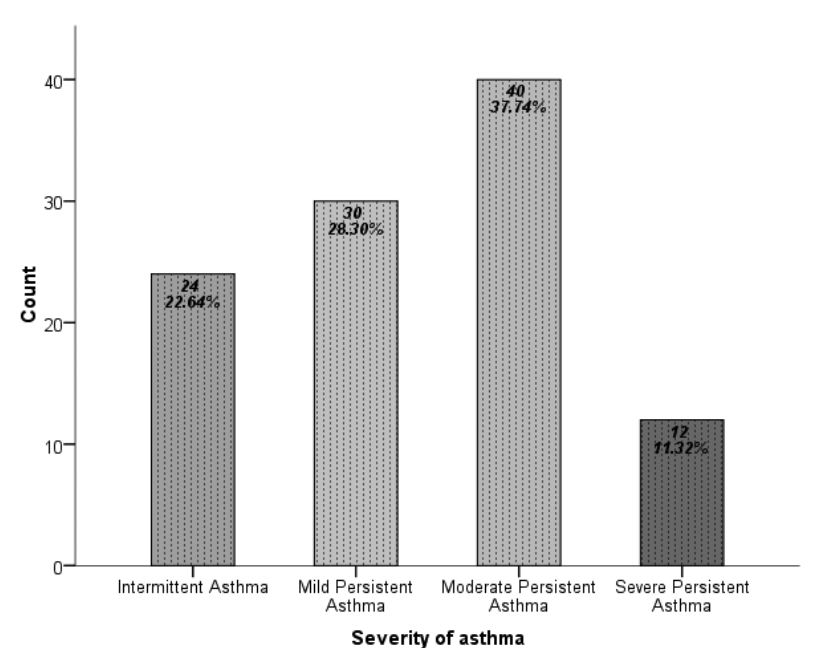

Figure-1. Frequency of severity of asthma in children $n=106$

\section{DISCUSSION}

Childhood asthma causes significant morbidity and results in School absence. There is no cure for this disease but the effective drug treatment is available which required a long time use of medicines. Asthma control can be possible with trigger avoiding measures and drugs. Drugs used for asthma treatment is classified as relievers (short acting beta agonists and anticholinergic agents) and controllers (Inhaled steroids, Long acting beta agonists and leukotriene receptor antagonists).

In our study a total of 106 children with asthma were included. Most of the children were below 10 years of age. Males were more common than the female. Moderate persistent asthma was most frequent and severe persistent asthma was least frequent. In an unsimilar study by Bacharier et al ${ }^{11}$ intermittent asthma was most frequent while moderate persistent asthma was less frequent, this difference may be due to age (they had more elder children). In a similar local study intermittent (32.6\%) and moderate persistent asthma (32\%) were most frequent, while severe persistent asthma was less frequent. ${ }^{12}$ Study by Leonard B et al showed unsimilar results than our study, mild intermittent asthma was most frequent. While moderate persistent asthma was least frequent. ${ }^{13}$ 
This difference may be due to, majority of children were taking controller therapy. A study conducted by Ali Ahmed et al in Lahore showed intermittent asthma, the most frequent severity and there was no child with severe persistent asthma ${ }^{14}$, this difference may be due controller therapy taken by children.

Gender influences airway responsiveness, in addition to its influence on lung function tests. Among children with mild to moderate asthma followed in the CAMP trial, airway responsiveness increased after puberty in girls, but decreased after puberty in boys. ${ }^{15}$ In our study frequency of severity of asthma was insignificant between male and female in contrast Weiss et al stated that the effects of asthma on lung growth are different for boys and girls. ${ }^{16}$

\section{CONCLUSION}

We found moderate persistent asthma, as the most frequent category, while severe persistent asthma was the least frequent category. Age had the significant effect on the asthma frequency; it was most common in less than 10 years old children. Duration of asthma and gender had no effect on asthma severity, while weight and height had a significant effect on asthma severity.

\section{RECOMMENDATIONS}

We need to improve awareness level of the patients, awareness level needs to improve in every healthcare sector at provider levels in an effort to categorize the asthma in intermittent or persistent. Evidence based practice and medicine incorporation in our health care system is vital for providing optimal care to the patients in an effort to not only yield positive patient outcomes but also to ensure that scarce therapeutic resources are efficiently and effectively utilized.

\section{Copyright $\subset 18$ Apr, 2019.}

\section{REFERENCES}

1. MacFarlane, J. The respiratory physician in a Third World district hospital. Br. Med. J., 1984; 289: 657.

2. Speight, N. The diagnosis and management of asthma in children. Practitioner, 1986; 230:549.
3. Shifren A, Witt C, Christie C, Castro M. Mechanisms of remodeling in asthmatic airways. J Allergy. 2012; 2012:316049.

4. Asher MI, Montefort S, Björkstén B, Lai CK, Strachan DP, Weiland SK, Williams H, ISAAC Phase Three Study Group. Worldwide time trends in the prevalence of symptoms of asthma, allergic rhinoconjunctivitis, and eczema in childhood: ISAAC Phases One and Three repeat multicountry cross-sectional surveys. The Lancet. 2006 Aug 26;368(9537):733-43.

5. Braman SS. The global burden of asthma. Chest. Jul 2006; 130(1 Suppl):4-12.

6. Datta A. News report. The News International. [Online]. 2012 [cited 31/05/2013]; Available From: URL:http:// www.thenews.com.pk/Todays-News-4-180873-10pcchildren-suffering-from-asthma-in-Pakistan.

7. Sahito A, Khan AA, Tanzil S, Jamali T, Shahid A, Naeem $S$, Siddiqui FA, Nafees AA, Fatmi Z. Burden of asthma among children in a developing megacity: Childhood asthma study, Pakistan. European Respiratory Journal 2015 46. DOI: 10.1183/13993003.congress-2015. PA1138

8. Mcfadden, ER, Gilbert, I.A. Asthma: Review article. N. Engi. J. Med., 1992; 327:1928-37.

9. BNF for children. 2012-2013. (BMJ group: Pharmaceutical press: RCPCH Publications, London, 2012).

10. Global Initiative for Asthma (GINA). Global burden of asthma report. [Online]. 2012 [cited 2013; Available From: URL: www.ginasthma.org.

11. O'Connor GT, Sparrow D, Segal MR, Weiss ST. Smoking, atopy, and methacholine airway responsiveness among middle-aged elderly men: The Normative Aging Study. Am Rev Respir Dis. 1989; 140:1520-6.

12. Jamalvi SW, Raza SJ, Naz F, Shamim S, Jamalvi SM. Management of acute asthma in children using metered dose inhaler and small volume nebulizer. $J$ Pak Med Assoc. 2006; 56:595-9.

13. Leonard B. Bacharier, Robert C. Strunk, David Mauger, Deborah White, Robert F. Classifying asthma severity in children, mismatch between symptoms, medication use, and lung function. Am J Respir Crit Care Med; 2004 (170): 426-32.

14. Ali Ahmed, Maria Tanveer, Gul Majid Khan, Kashif Hanif. Prescribing and utilization trends of anti-asthmatic drugs amongst children in a Tertiary Care Hospital in Lahore, Pakistan. Journal of Pharmacy Practice and Community Medicine. 2017, 3(2):70-75. 
15. Naqvi M, Choudhry S, Tasi HJ, Thyne S, Navarro D. Association between Ig - $E$ levels and asthma severity among African American, Mexican. Puerto Rican patients with asthma. J Allergy Clin Immunol. 2007; 120:137-43.
16. Weiss ST, Tosteson TD, Segal MR. Effects of asthma on pulmonary function in children. A longitudinal population-based study. Am Rev Respir Dis. 1992; 145:58.

\title{
Truth is always the strongest argument.
}

\author{
"Sophocles"
}

\begin{tabular}{|c|l|l|l|}
\hline \multicolumn{3}{|c|}{ AUTHORSHIP AND CONTRIBUTION DECLARATION } \\
\hline Sr. \# & \multicolumn{1}{|c|}{ Author(s) Full Name } & \multicolumn{1}{|c|}{ Contribution to the paper } & Author(s) Signature \\
\hline 1 & Muhmmad Athar Ahmed & $\begin{array}{l}\text { Hyperechogene, Data } \\
\text { analysis. } \\
\text { Proof reading, Final } \\
\text { approval, Critical analysis. } \\
\text { Methodology, Discussion. }\end{array}$ \\
\hline 3 & M. Nadeem Chohan & Nehan Adil Khan & Data collection. \\
\hline 4 & Tarim Nayab & \\
\hline
\end{tabular}

